\title{
Laudos antropológicos, responsabilidades sociais \\ Dilemas do reconhecimento de comunidades remanescentes de quilombos
}

Anthropological reports, social responsibilities

Dilemmas of recognition remaining quilombola communities

Rebeca Campos Ferreira*

Resumo: A reflexão volta-se aos impactos do processo de reconhecimento visando à titulação de terras de comunidades de quilombo, no âmbito do prescrito pelo Artigo 68 do ADCT/CF-1988. Neste sentido, visa refletir a respeito da emergência de novas categorias de sujeitos de direitos e seus efeitos socioculturais e políticos, para os grupos em questão e agentes envolvidos no processo, em campo marcado pelo conflito - de vozes, de interesses, de saberes e de competências. Aqui se destaca a relevância e o lugar do laudo antropológico de reconhecimento, seu percurso social e valor político, além do papel do antropólogo que atua nessa interface.

Palavras-chave: Comunidades remanescentes de quilombos; reconhecimento territorial; direitos étnicos; direitos sociais; laudos antropológicos

Abstract: This discussion proposes a reflection on the impacts process of recognition and titling processes of Quilombo communities, according to the prescription of the Article 68 of the Constitution of Brazil. The proposal reflects on the emergence of new categories of legal subjects and sociocultural and political effects for the groups concerned and involved in the process. Here stands the importance and place of the anthropological report of recognition, the trajectory of its social and political value route, and the role of the anthropologist who works on that interface.

Keywords: Quilombo communities; territorial recognition; ethnic rights; social rights; anthropological reports

* Doutoranda do Programa de Pós-Graduação em Antropologia Social na USP. <rebecca. campos@gmail.com>.

\begin{tabular}{|l|l|l|l|l|l|}
\hline Civitas & Porto Alegre & v. 12 & n. 2 & p. 340-358 & maio-ago. 2012 \\
\hline
\end{tabular}




\section{Apresentação}

O presente trabalho propõe uma reflexão sobre impactos do processo de reconhecimento visando à titulação de terras de comunidades de quilombo, no âmbito do prescrito pelo Artigo 68 do Ato das Disposições Constitucionais Transitórias (ADCT) da Constituição Federal (CF) do Brasil de 1988. ${ }^{1}$ $\mathrm{O}$ processo em questão, realizado pelo Estado, tem por objetivo expedir aos remanescentes de comunidades quilombolas os títulos respectivos de propriedade coletiva, sendo pautado em laudos periciais antropológicos. Volta-se à possibilidade de acesso a um direito de caráter coletivo, étnico e fundiário, que remete à construção identitária, na medida em que o preceito constitucional pressupõe a emergência da identidade quilombola, em que pese a ressemantização do conceito, para fins da aplicabilidade legal.

Neste sentido, visa refletir a respeito da emergência de novas categorias de sujeitos de direitos e seus efeitos socioculturais e políticos, para os grupos em questão e agentes envolvidos no processo, em campo marcado pelo conflito - de vozes, de interesses, de saberes e de competências. Aqui se destaca a relevância e o lugar do laudo antropológico de reconhecimento, seu percurso social e valor político, além do papel do antropólogo que atua nessa interface.

\section{Regulamentação jurídica das identidades}

O quilombo, como direito, é uma espécie de potência que atravessa a Sociedade e o Estado em suas mais diversas formas: ele embaralha as identidades fixas, a configuração do parentesco, da região e da nação e instaura a dúvida sobre a capacidade do Estado em ser o gestor da cidadania e o ordenador do espaço territorial (Leite, 2008, p. 277).

A atribuição da identidade quilombola a determinado grupo e os direitos que dela decorrem levam ao redimensionamento do próprio conceito de quilombo, e também dos conceitos de identidade, etnicidade e territorialidade. No momento em que o Estado reconhece um grupo como remanescente, fixa identidade política, administrativa e legal, e ainda identidade social, que remete à identificação étnica, enquanto veículo de obtenção de direitos diferenciados. Desse modo, o artigo 68 do ADCT/CF-88 institui novo sujeito social e político, etnicamente diferenciado a partir dos direitos instituídos. Este novo sujeito é criado no contexto de lutas sociais que fazem da lei o seu instrumento, tendo a

O Artigo 68 do ADCT/CF-88 disserta que "Aos remanescentes das comunidades dos quilombos que estejam ocupando suas terras é reconhecida a propriedade definitiva, devendo o Estado emitir-lhes os títulos respectivos". 
conversão simbólica do conceito de quilombo, que é metamorfoseado e ganha funções políticas. A categoria jurídica "remanescente de quilombo" é criada e institui a coletividade enquanto sujeito de direitos fundiários e culturais (Arruti, 2003). Tal disposição do Estado em institucionalizar a categoria pode ainda ser tomada na perspectiva de uma tentativa de reconhecimento formal de uma transformação social considerada como incompleta, o que revela distorções sociais de um processo de abolição da escravatura parcial e limitado (Almeida, 1997).

Fora necessária a ressemantização do conceito de quilombo para aplicação do Art. 68, na medida em que novas figuras legais penetram, pelo preceito, o direito positivo, "através dessas rachaduras hermenêuticas que são os direitos difusos" (Arruti, 1997, p. 01), sendo preciso discernir critérios de identificação das comunidades remanescentes, nos planos conceitual e normativo. Em universos distintos, são impactados os campos da análise científica e da intervenção jurídica. O conceito de quilombo vai além da categoria histórica para abranger variedade de situações de ocupação de terras por grupos negros, para além do binômio de fuga e resistência. Enquanto agentes coletivos na dinâmica social, os remanescentes de quilombo devem ser tomados em sua dimensão política, entre as quais perpassa a noção de identidade. E por partilharem origem, cosmologia e ancestralidade ganham visibilidade política a partir de uma identidade genérica que lhe é atribuída, passando a compartilhar também um mesmo universo jurídico, político e cognitivo (Arruti, 1997).

A aplicação do Art. 68 gera demandas especificas frente à comunidade que dele fará uso - a complexidade das situações então, é pautada na oposição entre a generalidade da lei e a peculiaridade do caso - singularidade que envolve uma gama de abordagens delicadas e dotadas da especificidade histórica que formara e fora responsável pela manutenção dessa comunidade até o presente, em trajetórias marcadas por conflito e exclusão, sendo que, desde a Constituição de 1988, esse quadro pode ser revertido na possibilidade de acesso a direitos diferenciados. São ainda, as comunidades remanescentes de quilombo tomadas como categoria social recentemente posta - já que instaurada a partir da Constituição - e marcada pelo caráter pluralista do reconhecimento de diferenças.

Nesse contexto, o Art. 68 do ADCT é dispositivo constitucional que dá sentido de existência coletiva, sendo categoria temporal, visto que é situacional e contingencial (Almeida; Pereira, 2003). Categoria que representa força social no que diz respeito à luta por demandas territoriais - e outros direitos decorrentes - em desdobramentos que atingem políticas públicas e 
ações direcionadas, relacionadas ao campo das ações afirmativas, programas e projetos específicos. Tudo isso é permeado por pressões e embates políticos e econômicos, em formulações e reformulações jurídicas e administrativas, no que concerne ao reconhecimento e à titulação, em meio às exigências quanto à organização política.

Por se tratarem de terras ocupadas segundo moldes específicos, por vezes não possuem contraponto jurídico, administrativo ou legal e frequentemente estão sobrepostas a interesses econômicos. Novos mediadores políticos e especialistas passam a integrar a cena; o conjunto de leis e normas executado pelos órgãos oficiais exige clareza, ordenamento, delimitações e pressupõem espaços bem marcados com identidades visíveis - o que nem sempre é possível. O reconhecimento se dá na esfera política, onde se faz necessário criar uma imagem do grupo como coeso, homogêneo e portador de demanda clara, bem como de limites territoriais definidos, o que diz respeito à própria autodefinição enquanto tal categoria, de onde decorrem adaptações e conflitos, divergências internas e adequação aos procedimentos. Precisa-se da definição de um território reivindicado, e metros quadrados vêm ocupar o que outrora foram marcas de outras ordens, em outra lógica de propriedade. Deve ser levada em conta a tendência que os processos administrativos carregam de imobilizar fronteiras fundiárias ao fixá-las em modelos cartográficos, de modo a, por vezes, não coincidirem com a experiência vivenciada pela comunidade. A posse da terra é repertório de expressões peculiares que se distinguem das disposições jurídico formais de propriedade e titulação, evidenciando territorialidades carregadas de especificidades que fogem à estrutura agrária de organização fundiária (Stucchi; Ferreira, 2010).

Um novo horizonte se abre com o 'redescobrimento' da história e com a emergência de novos direitos. Um conjunto de direitos e deveres compartilhados e integrados ao cotidiano passa a ser sobreposto a uma nova gama de direitos formais apresentada pelo processo de reconhecimento jurídico da comunidade como remanescente de quilombo. Entretanto, para que tenham efetivo acesso aos direitos, devem agregar novas óticas, mudar viés, adotar novas práticas, sendo confrontados com limites dados pela generalidade da lei, em novo jogo reinterpretativo que se articula, soma, conflita ou complementa ao que fora compartilhado e construído no decorrer do tempo. O processo de construção identitária é espelhado diante da nova moldura formal à qual se ajusta. A identidade do grupo se reconstitui, em dinâmica múltipla, que recombina facetas. O grupo deve passar por um movimento de recomposição e reorganização quando lançado frente à categoria jurídica "remanescente de quilombo"; são novas categorias classificatórias, apropriadas e ressignificadas. 
Condições que dizem respeito à complexidade do processo de reconhecimento de comunidades como remanescentes de quilombo.

Pode-se então pensar acerca do processo jurídico e político de titulação dessas comunidades sob o ângulo dos grupos alcançados pelo direito: categoria jurídica que garante acesso a direitos, mas não abarca singularidades. Em suma, a ênfase recai na regulamentação jurídica da identidade, a partir do reconhecimento oficial realizado pelo Estado com base no Art. 68 do ADCT, quando elementos da identidade ganham novos pesos, o que leva à problematização do modo pelo qual as comunidades em processo de reconhecimento respondem às imposições, formalidades e distinções dadas pela lei genérica, e modo pelo qual o processo impacta no peculiar cotidiano social do grupo.

O quadro apresentado leva à reflexão sobre os diferentes modos de construções identitárias e sujeitos políticos que emergem dessas novas fórmulas jurídico-institucionais oriundas do texto constitucional. Ocorrem mudanças relativas aos modos pelos quais as comunidades reagem ao estatuto do sujeito político, diante de seus próprios modos de interação. Observam-se exigências quanto à participação e à conversão política, necessidade de consolidação legal de uma associação representativa, o que muitas vezes contraria a própria dinâmica que movimenta relações internas às comunidades.

Tal como os procedimentos, a gramática é universalizante; o idioma do Direito atribui identidades genéricas a grupos peculiares, e do recurso a estas identidades decorre o acesso a direitos diferenciados. Um duplo movimento nos problemas implicados no reconhecimento de grupos étnicos: estes devem ser - e são - tomados pelo Estado como ideais, e devem, por conseguinte, se enquadrar nessa generalidade, o que por sua vez remete a manobras internas para que se façam enquanto pede a categoria jurídica, que possam assim ter seus direitos efetivamente reconhecidos.

Fatos que devem ser observados e trabalhados pela sensibilidade do antropólogo em campo, mas que para o preceito constitucional e para o título de propriedade que dele resulta não existem, pois esses grupos e indivíduos são tomados como ideal e abstratamente unos (Stucchi; Ferreira, 2010, p. 20).

Um outro movimento é parte do processo,

O reconhecimento [...] implica a apropriação dessas mesmas categorias como categorias políticas, jurídicas e administrativas genéricas e generalizáveis. Tal criação não implica, por sua vez, o simples transporte do vocábulo de um universo semântico ao 
outro, na medida em que, ao ser absorvido por esse novo campo discursivo, ele entra em uma estrutura de significação que lhe atribui significados particulares (Arruti, 2006, p. 44-45).

Segundo Arruti (2006), o que se tem é a redefinição da própria alteridade, uma vez que a emergência do quilombo surge como metáfora política socialmente produtiva, e se vê a recaptura da categoria jurídica pela lógica política, na associação a um novo paradigma. A alteridade que não mais se expressa somente nos termos da diferença, mas também através das identidades; das alteridades dadas são feitos fatos, ou seja, a alteridade se torna um dado, construída através dos discursos.

Nesse sentido, o termo remanescente de quilombos pode ser tomado enquanto forma genérica de identificação, de caráter essencialmente jurídico, que é atribuída pelo Estado, todavia, há a circunscrição de um espaço para as reivindicações no exercício da luta política por parte das comunidades negras e de suas organizações, baseada na autoatribuição (Arruti, 2006). E laudos antropológicos de reconhecimento têm o seu lugar no emergir das comunidades, se apresenta como escrita e fato político, e por isso deve-se considerar a arena de emergência deste próprio documento. É um jogo de forças, onde a categoria "territórios negros", oriunda de meios acadêmicos, transfigura-se na categoria jurídica e política "comunidades remanescentes de quilombos", para permitir que uma população possa ser politicamente pensável:

Verdadeira alquimia - que transforma uma matéria acadêmica em substância política e para cuja formatação todo um conjunto de agentes se engaja - as lutas em torno da questão das comunidades remanescentes coloca em exercício local as mais delicadas questões da relação entre as ciências sociais e o mundo político (Anjos, 2005, p. 98).

No processo de reconhecimento, tal como posto por Arruti (2006, p. 126), a comunidade enquanto sujeito coletivo assim institui-se como sujeito de direito diante de instituições, normas e procedimentos administrativos, e como sujeito público. Há intervenções, “é essa ação de mediação que institui a ponte entre uma gramática local da dominação e uma gramática extra local dos direitos fundamentais, e como parte desse, os direitos étnicos". E desse modo chega-se à semântica coletiva, onde se figuram dois planos de intervenção, um voltado a agentes que politizam conflitos e os reenquadram categoricamente, e outro referente à intervenção de um discurso autorizado e especializado, este responsável por legitimar tal reenquadramento, de modo que ele tenha eficácia jurídica. 
O processo de reconhecimento pressupõe a emergência da identidade quilombola, de modo que comunidades, marcadas por exclusão e conflitos, devem fazer do estigma a sua bandeira de luta. Na emergência de novos sujeitos políticos portadores de direitos diferenciados, o espaço é marcado por diversas vozes e interesses, onde se destaca a presença de mediadores com o intuito de aprofundar a compreensão das regras estabelecidas, das quais depende o acesso a direitos. Contudo, as relações de intermediação são, por vezes, assimétricas no que diz respeito à distribuição de poderes.

São dificuldades e dilemas que compõem o cenário do processo de reconhecimento, com seus vários agentes. É preciso considerar que o processo de mediação que imputa a esses agrupamentos a definição de "remanescentes" precisa encontrar neles condições, objetivas e subjetivas, para colocá-los como "quilombolas" e acionar o Art. 68: vai-se da negação à afirmação positiva da identidade estigmatizada.

\section{Laudos antropológicos, responsabilidades sociais}

Nesse cenário inserem-se os laudos e relatórios de identificação étnica, elaborados enquanto diagnósticos de situações sociais para que orientem as intervenções na aplicação dos direitos constitucionais. O profissional que aqui atua deve expor as concepções próprias às formas de autodefinição do grupo, sua percepção de espaço, usos e valores, em documentos que não têm caráter de atestado; são tomados enquanto documento-síntese, cujo papel volta-se à formulação de parâmetros futuros para mediação dos trabalhos, considerando ainda que questões de ordem interpretativa podem produzir impactos do ponto de vista da aplicação das leis e das situações vividas pelos grupos envolvidos, frequentemente em desequilíbrio de poder.

Nesse âmbito, devem-se levar em conta as relações entre trabalho técnicocientífico e trabalho político, considerando que, em situações de perícia, o antropólogo se depara com múltiplas versões e variados atores, devendo assumir uma posição onde tenta sistematizar tais versões - estas que podem ser divergentes dentro do próprio grupo - e torná-las inteligíveis para o juiz. É a responsabilidade da produção de um laudo - com seus desdobramentos políticos - que irá permitir o reconhecimento de direitos territoriais do grupo de acordo com o preceito constitucional, e do qual decorrem outros, intrincados, direitos, e por vezes não claramente compreensíveis.

O laudo sofre apropriações institucionais e políticas, onde se tem a operacionalização de conceitos da antropologia como forma de dar cumprimento às exigências dadas pelo campo jurídico. Esses documentos serão meios de constituir provas, convencimentos e legitimação de reivindicações: 
apropria-se de um saber especializado, em múltiplos usos possíveis que podem ser feitos da Antropologia em políticas de reconhecimento de direitos étnicos, onde o cenário é marcado por disputas, contradições e tensões verificados no âmbito da Antropologia e que se refletem na construção dos processos reivindicatórios (Stucchi, 2005).

Com relação ao laudo ser considerado modalidade de produção científica, O’Dwyer (2005) o toma enquanto tal por suas próprias condições de elaboração, pelo fato de inserir-se em um processo, ser parte de um diálogo com outros campos e saberes, e ser produzido mediante quesitos previamente elaborados. $^{2}$

Os laudos orientam a tomada de decisões concretas, cujos desdobramentos podem alterar a vida de comunidades inteiras. A solicitação desse tipo de trabalho espera exatidão técnico-científica, de modo que propicie medidas, estas com desdobramentos múltiplos. É nesse sentido que Leite (2006) toma os laudos como documentos produzidos com finalidades previamente estabelecidas, uma vez que são dirigidos ao que chama de audiência restrita, são dotados de regras que são determinadas pelas instâncias onde irão tramitar, e podem ainda ser submetidos às análises e avaliações específicas. ${ }^{3}$

Merecem breves considerações acerca da Carta de Ponta das Canas, elaborada em 2000, a partir da Oficina sobre Laudos Antropológicos, promovida pela Associação Brasileira de Antropologia (ABA). Este documento foi gerado com o intuito de servir como parâmetro ao Protocolo de Cooperação Técnica que a ABA firmava com a Procuradoria Geral da República. E assim tornouse, para as atividades de perícia, uma referência, embora se ressalte que não possui caráter normativo, devendo servir a parâmetros iniciais. Nela indica-se que laudos não têm caráter de atestado e devem ser diagnoses das situações

2 Recorre-se ainda à definição proposta por Carreira (2005), que diferencia perícia, laudo e relatório. A perícia seria um parecer técnico especializado, opinião fundamentada sobre determinado assunto, ao passo que o laudo se constituiria na peça escrita em que o especialista expõe suas observações sobre os estudos realizados e registra conclusões, com o objetivo de responder a um conjunto de quesitos previamente explicitados pela instituição solicitante. O laudo cumpre a função de orientar o processo administrativo ou jurídico. Já o relatório não seria resultado de perícia, constituindo-se numa descrição ordenada, até verbal, sobre aquilo que se testemunhou. Em tese não é necessário ser cientista para fazer um relatório, mas quando se trata de uma solicitação dirigida a alguém enquanto especialista, tal resposta pode ser concebida como um laudo e considerada, portanto, perícia. Ainda nesse sentido, Leite (2002, p. 17) define um laudo como sendo "o resultado final de uma perícia".

3 Vale acrescentar que todas as partes envolvidas terão livre acesso a ele, uma vez que o documento poderá se judicializar, ser parte de processo legal que possui o direito de contraditório. Nesse ponto, a reflexão já aponta para o atuar do profissional da antropologia, que irá expor informações, ciente das leituras que possam ser feitas. Ou seja, além das singularidades desse tipo de trabalho, aqui já apresentados, há um caráter ético fortemente marcado. 
sociais investigadas, que orientem e balizem as intervenções governamentais na aplicação dos direitos constitucionais (ABA, 2000, p. 12). ${ }^{4}$

Porém, não se pode perder de vista a contribuição do laudo como intervenção mediadora, uma vez que favorece o equilíbrio de poder entre as múltiplas forças em jogo, mas sempre na sutileza de tomar narrativas diversas, que vem do contexto da elaboração de reivindicações territoriais, porosas e sobrepostas.

Tal como posto por Becker (2005, p. 255):

O processo de sua confecção encontra-se permeado por três conflitos relacionais (tensões) básicos: entre os operadores jurídicos e o antropólogo, entre o antropólogo e os informantes e finalmente, entre os próprios informantes. O conflito (ou tensão) presente na relação estabelecida entre os conhecimentos jurídico e antropológico, como bem aponta a Carta de Ponta das Canas (2000, p. 9) é parte das ferramentas próprias de cada um, expressando diferentes poderes, ainda que desiguais.

Merece ser posto que laudos são demandados em situações especificas, de modo que terão conteúdos e contornos distintos, além do que é produto de situações etnograficamente específicas. E sendo assim, não há metodologia que dê conta dos diferentes processos e contextos onde se inserem este tipo de pesquisa, tampouco se prevê os usos políticos que delas se fazem. O que já fora posto por Barcellos (2005) é que frequentemente a pesquisa caminha em meio à demanda. Para Lopes da Silva (1994), a pesquisa voltada à produção de um laudo pericial é elaborada pelos procedimentos próprios da disciplina, com mesmo rigor; todavia produz conhecimento não aplicado, e sim aplicável, que responde às questões concretas. Já segundo Stucchi (2005, p. 307-308), o laudo baseia-se em um conjunto de questões postas ao perito, estas que são oriundas da realidade concreta e orientadas pelo curso do conflito. Sendo assim:

O laudo pode ser uma peça que contém elementos metodológicos próprios da pesquisa antropológica, formulações oriundas das teorias antropológicas e apropriação de fontes em base à experiência analítica da disciplina, indaga-se onde e até que ponto reside e sustenta-se a diferença entre a atividade pericial e a atividade antropológica para fins de pesquisa pura.

4 Os debates que orientaram a oficina seguiram três linhas, a saber: referentes aos paradigmas (campo teórico, conceitual e interlocutores disciplinares), aspectos técnicos (trabalho de campo, recorte e conteúdo, literatura e estrutura do documento) e ética (lei, autoridade, saberes, tradução e interpretação, ação política, políticas), no que diz respeito a três eixos temáticos (laudos sobre delimitação territorial, laudos sobre identificação étnica e laudos sobre impactos sócioambientais e grandes projetos). 
Assim, vai-se aos limites e possibilidades de interlocução entre o conhecimento jurídico e o conhecimento antropológico, ambos voltados à defesa de grupos sociais, cujo pano de fundo é o tratamento dado pelo Estado ao reconhecimento jurídico das diferenças étnicas. Age-se, portanto, no espaço político - e constitucional - da diferença, onde se faz necessária a percepção dos fatos a partir de uma outra dimensão, esta que seja capaz de incorporar o ponto de vista dos grupos sociais que pretendem fazer valer o direito atribuído pela Constituição.

\section{Interface de saberes em situações de perícia}

Os diálogos com o campo jurídico, aqui abordados a partir do reconhecimento de comunidades remanescentes de quilombos, se dão ainda em diversos outros momentos e situações nas quais o direito recorre ao suporte de pesquisas antropológicas. E em todos esses casos, durante o processo de reconhecimento oficial, entram em interação diversos órgãos governamentais e não governamentais, especialistas, movimentos sociais, que impactam sobre os grupos, juntamente às mudanças que vêm associadas a esse processo.

A reflexão volta-se à produção de laudos antropológicos, requeridos nesses processos, aonde vem à tona tanto o papel do antropólogo perito quanto da própria Antropologia, nesse contexto frequentemente marcado pelo conflito, no âmbito da política do direito à diferença e no cenário de reconhecimento de especificidades socioculturais e históricas. Vê-se a crescente importância da perícia antropológica, em temática de relevância social e política, em contextos específicos e em relação com instituições. Aqui se atenta ao relacionamento entre a Antropologia e o Direito, e aos dilemas dessa atuação realizada na interface.

A emergência desses novos sujeitos é acompanhada pela emergência de uma variedade de assessores, consultores, organizações, órgãos públicos, com atribuições renovadas e profissionais que são lançados em campo de disputas territoriais, étnicas e éticas.

No jogo de éticas e de poderes em conflito, no âmbito da arena originada com a defesa de interesses e direitos de novas identidades, os antropólogos e os operadores do direito estão diante de um desafio, que pode ser traduzido pela criação de novos espaços de diálogos possíveis e marcados pela inteligibilidade entre duas tradições de pensamento visando, para começar, a ampliação da compreensão sobre as diferenças que habitam o mundo e a criação de espaços válidos para acomodar essas diferenças (Stucchi, 2005, p. 358). 
O que Arruti (2005, p. 129-130) coloca como a particularidade da situação de perícia é o estabelecimento de um contrato onde os termos, contraditórios entre si, já são estabelecidos inicialmente,

Ao entrar em campo para uma perícia ou para um laudo, ele já está vinculado, de um lado, a um determinado conjunto de demandas do grupo (ou da fração do grupo ligada a tais demandas) e, de outro, comprometido com um padrão de persuasão discursiva próprio às instâncias do Estado, pautado pelos critérios de verdade e pela linguagem administrativos ou jurídicos.

Pode-se ainda refletir sobre o espaço dos laudos antropológicos nesses processos: são solicitados em procedimentos, judiciais ou administrativos, para identificação e reconhecimentos das comunidades; contudo, o ponto de partida é a formulação jurídico-institucional, voltada à necessidade de 'identificar' titulares do direito assegurado. Sendo assim, somente a manifestação de autoatribuição étnica não assegura por si só o reconhecimento oficial, ou seja, permanece a necessidade da prova, tão cara ao direito e tão distinta no fazer antropológico. Espera-se a prova etnográfica, e o antropólogo deve estar habilitado a assessorar a comunidade no sentido de incluir as demandas adequadamente. A autodefinição é, portanto, acompanhada por estudos técnicos especializados que servem no sentido de descrever e interpretar a formação de unidades étnicas no contexto de processos de reconhecimento de comunidades remanescentes de quilombos; estudos estes que tragam subsídios para decisões pautadas pela Constituição; tal como posto por Ribeiro (2003, p. 286):

Do contrário corre-se o risco de possibilitar apenas a reprodução das relações e categorias sociais que se definem levando em conta o preceito constitucional, sem garantir as condições para a perpetuação das tradições culturais e dos modos de vida dos grupos que reivindicam o direito à diferença.

No reconhecimento faz-se necessária a comprovação técnica da identidade e da territorialidade, produção que cabe aos profissionais especialistas acadêmicos, e assim pode-se problematizar o próprio direito a autoatribuição. Laudos que fazem recurso à bagagem teórica antropológica, em contextos de demandas sociopolíticas, e são postos frente a lógicas de áreas outras, engendrando assim embates conceituais.

[...] o antropólogo se vê obrigado a responder a demandas políticas, jurídicas ou administrativas, o desafio está em manter-se critico 
aos limites impostos pela lógica desses mesmos campos à analise antropológica (que eles solicitam, porém raramente são capazes ou estão dispostos a aceitar em toda sua extensão). [...] Ele também impõe a dificuldade de ter que responder objetivamente a tais demandas a partir de um outro critério de objetividade (jurídico) sem ceder à força de objetificação que elas pretendem impor (Arruti, 2006, p. 33).

A técnica jurídica pressupõe a evidência, se volta ao oferecimento de um prova ou contraprova, por intermédio de circunstâncias externas relacionadas de acordo com o ponto de vista do observador. Já no fazer antropológico, a sociedade é tomada em seu contexto, por categorias e valores que são próprios dos grupos. Em Antropologia,

A prova sobre a diversidade nos modos de existência coletiva é a evidência etnográfica construída a partir das categorias êmicas do grupo e de seus valores internos [...]. De que maneira transformar a terminologia dos nativos em terminologia técnica, quer dizer, em conceitos sociológicos? (Tomke Lask, In: Barth, 2000, p. 11). Para Barth, depende do contexto local em que esses termos estão inseridos e devem ainda ser levados em conta os significados variados que podem ter numa mesma sociedade (O'Dwter, 2006, p. 235).

Assim pode-se remeter a Geertz (1998), no sentido das sensibilidades jurídicas, que seria o modo de tradução, das instituições jurídicas, da linguagem de imaginação - normas genéricas - à linguagem da decisão - casos concretos, onde se cria um sentido de justiça singular. Ainda segundo o autor, no tomar processos judiciais como artefatos culturais, o que se tem é a simplificação dos fatos vividos de modo que se enquadrem às normas. Isso seria uma redução a termos, e o próprio processo é tomado como uma descrição de mundo normativa, o dever ser, e o Direito surge como uma, dentre tantas, visões de mundo. Decorre que não há somente uma sensibilidade jurídica, e formas locais operam através de variadas gramáticas. A questão que fica diz respeito aos encontros e desencontros das sensibilidades jurídicas locais com as sensibilidades jurídicas dos agentes envolvidos.

Um dos apontamentos da referida Carta de Ponta das Canas (ABA, 2000), coloca como um dos maiores problemas no relacionamento dos antropólogos com as demandas do campo jurídico e administrativo, aquele que diz respeito à alteridade entre os campos conceituais, que toma forma por meio da dualidade entre produzir julgamentos e produzir inteligibilidade; produzir verdades ou interpretações; e, ainda, operar a hermenêutica do código legal para aplicação 
objetiva de um ordenamento jurídico nacional ou realizar descrições densas da realidade local, que dificilmente podem fugir de suas aplicações contextuais. As tensões entre os campos também remetem às ferramentas de cada um. Ressalta-se que o antropólogo não figura enquanto juiz ou detetive; logo seu trabalho não irá mostrar uma verdade, e sim "traduzir uma realidade não imediatamente compreensível, particularmente pela cultura jurídica" (ABA, 2000, p. 36). Há ainda outros dilemas, no que toca ao tempo transcorrido entre a elaboração do trabalho de campo, o laudo e o próprio processo em que ele está inserido; são, pelo menos, três tempos distintos: o tempo da comunidade, o tempo do trabalho antropológico e o tempo da justiça.

\section{Antropologia e antropólogos na interface}

Pode-se, ainda, refletir acerca das relações do fazer Antropologia em laudos com ofazer Antropologia na academia. Vale ser posto que pela atuação desses profissionais atenuam-se as fronteiras entre trabalhos realizados dentro e para a academia, e fora dela, "prevalecendo um ziguezaguear constante entre a inserção no mundo acadêmico e os chamados saberes aplicados, que envolvem o campo político de aplicação dos direitos constitucionais e do exercício da cidadania" (O’Dwyer, 2005, p. 216). Ao se fazer antropologia em situações de perícia, tal como coloca Leite (2006, p. 18):

Consolidava-se o reconhecimento oficial do antropólogo como um agente capaz de produzir laudos com a finalidade de municiar processos jurídicos e administrativos, fazendo ressoar no interior da disciplina novas questões de ordem ética, teórica, metodológica. Afinal, a antropologia estava diante da ampliação do conceito de Justiça.

Problematiza-se ainda o caráter de perícia coadjuvante que o laudo pode assumir, o que para Anjos (2005, p. 110-111) só se evita se o caráter de intervenção acadêmica junto às arenas do Direito for enfatizado, ou seja,

Se for capaz de se fundamentar epistemologicamente a partir de uma perspectiva pragmática que evita a questão da neutralidade, que relativiza a hierarquia dos discursos instituídos e que aprofunda substancialmente as perspectivas nativas em jogo, buscando recursos argumentativos, inclusive nas tradições jurídicas e filosóficas que estão fora do horizonte de justiça local. [...] num sistema de explicitação da expectativa de justiça jamais formulado completamente pelo ator em questão. 
Esse fazer Antropologia em uma nova configuração de saberes abre um campo de pesquisa que conjuga o envolvimento das comunidades pesquisadas, dos pesquisadores de várias áreas, militantes de movimentos sociais, profissionais de entidades e instituições públicas. Os limites colocados ao trabalho do antropólogo, nesse contexto, dizem respeito ainda ao reconhecimento dos limites de abrangência do trabalho antropológico.

Ao se deparar com questões que nem sempre podem ser respondidas, ao lidar com a expectativa de que possa formular as respostas que conduzam à solução de confrontos entre interesses e direitos, o antropólogo tem também que lidar com os limites da sua própria disciplina. Sua tarefa continua sendo não a de "fornecer uma classificação verdadeira, mas sim descobrir a lógica de constituição das classificações e os jogos que se estabelecem entre elas" (Oliveira Filho, 1994, p. 128). Esse exercício de contenção da autoridade antropológica permite, ao mesmo tempo, que o antropólogo não se substitua aos atores sociais - não entrando no jogo das classificações em disputa para definir fronteiras reivindicadas por eles próprios - e não se substitua à autoridade do juiz (Stucchi, 2005, p. 313).

São postos os desafios à prática antropológica, que deve ainda problematizar as categorias jurídicas, marcadas pela generalidade, tal como a categoria 'remanescente de quilombo', e aplicá-las a casos concretos, para que depois retornem às mãos da tomada de decisões. Há dilemas na aplicação, onde está em jogo o caráter generalizador - e por vezes redutor - da mesma categoria jurídica que gera direitos, de onde decorrem dificuldades próprias ao processo de sua interpretação.

Desse modo, fazer Antropologia circunscreve-se aos direitos inerentes às populações que são pesquisadas pelos antropólogos, assim como aos deveres, responsabilidades e direitos inerentes aos próprios antropólogos. E no caso dos antropólogos que atuam na interface da Antropologia com o Direito acrescentam-se outros dilemas, inerentes ao contexto no qual se realiza o trabalho, no que se refere à instituição que o demanda.

Trata-se, portanto, de um contexto onde a defesa dos direitos coletivos está atrelada à atuação do antropólogo, cujo conhecimento é tido como necessário à orientação da tomada de decisão em outros âmbitos institucionais (Stucchi, 2005). Ao profissional cabe subsidiar processos jurídicos e administrativos, em contextos específicos, em situações-limite e de interface entre saberes. $\mathrm{O}$ produto de seu trabalho deve nortear as possibilidades de atuação da instituição, no que diz respeito a situações concretas, onde estão em jogo os direitos e interesses de grupos socioculturais. Os antropólogos vão 
ao cenário jurídico, seja por chamadas ministeriais ou de outras instituições, para "tornar inteligíveis certas situações que jamais podem ser entendidas fora de seu contexto sóciocultural" (Leite, 2001, p. 34). Situações estas que dizem respeito ao reconhecimento de direitos constitucionais, e por vezes à própria continuidade de grupos. Figura-se, assim, mais um fazer da antropologia, no diálogo com outros saberes, que, por um lado, pode separar-se do fazer Antropologia na e para a academia, embora guardem muitos pontos em comum.

Desse modo, cabe ao antropólogo o diálogo com o grupo, passando ainda pela definição dos limites do território, que deve ser justificado a partir de dados etnográficos em combinação à bagagem teórica, em uma escrita que deve ser inteligível aos profissionais do direito envolvidos. Tendo ainda que o documento produzido será também lido pela outra parte em litígio, e terá desdobramentos. Intensifica-se assim o debate acerca dos limites do trabalho de perícia e sobre o papel do antropólogo na identificação dos grupos sociais envolvidos, estes que têm voz própria, são possuidores de um 'saber' acerca de si mesmos, dotados de formas organizativas e de plena capacidade de expressão (Leite, 2006).

A situação de perícia remete a dilemas quanto à expectativa gerada do trabalho do antropólogo, no contexto de complexo jogo de pressões, negociações e disputas entre diferentes grupos sociais, o que pode levar à confusão do papel desse profissional enquanto árbitro ou mediador. A expectativa pode vir tanto do lado dos profissionais do Direito quanto da comunidade, esta que pode ver no perito aquele que solucionará questões de longa data.

Ao antropólogo tem-se atribuído o papel de um classificador externo que, de modo naturalizado, identifica as unidades sociais e culturais. Nesse contexto, faz-se necessário romper com os preceitos positivistas que fundamentam esta demanda e ter em vista que, ao profissional da antropologia, cabe a explicitação das categorias nativas, bem como propiciar a relação entre categorias étnicas formalizadas juridicamente e categorias próprias às comunidades em questão. O que se tem é uma prática antropológica empenhada em produzir um exercício interpretativo daquela realidade e que permita a aplicabilidade de direitos constitucionais, que se faça a partir de um diálogo com as práticas culturais de cada grupo envolvido para que as exigências legais, que acompanham a política de reconhecimento, possam corresponder e entrar em adequação com o modo de vida dos grupos (Dallari, 1994; Oliveira Filho, 1995; Stucchi, 2005). Nesse âmbito Leite (2006, p. 50) coloca que:

Todas essas exigências internas e externas ao campo periciado representam um pesado ônus - emocional, inclusive - a recair sobre os ombros do antropólogo. Muitas vezes lhe é cobrado um 
papel quase que de árbitro, de alguém que deve determinar o que e como se deve proceder. Embora suas conclusões sejam frutos do contato com as comunidades pesquisadas, nem sempre tais grupos concordarão ou acolherão seu ponto-de-vista. Invariavelmente encontramos situações em que o papel do antropólogo é super ou subdimensionado, o que implica, em última instância, num desrespeito à sua condição de especialista.

Ribeiro (2003) indica que os antropólogos, aos assumirem sua responsabilidade social, fazem desse saber experimental um instrumento de reconhecimento público de direitos. Assim, a participação destes profissionais representa um tipo de intervenção em um campo específico de articulação e envolvimento do mundo intelectual com movimentos sociais e mobilização de grupos étnicos. Nesse sentido, para Arruti (2005) a situação de perícia figura como:

Situação privilegiada para a reflexão sobre a pesquisa desenvolvida em intenso diálogo não só com os campos político e jurídico (situação que nunca esteve ausente da história de nossa disciplina), mas com as demandas dos próprios "objetos" de estudo (aí, sim, temos algo relativamente recente), cada vez menos satisfeitos com o lugar de objeto que nosso habitus acadêmico continua lhes imputando (Arruti, 2005, p. 116).

Atenta-se às implicações jurídicas, administrativas e políticas, levando em conta desdobramentos e reapropriações. Daí se chega à responsabilidade social que carrega a prática da perícia antropológica, "sobretudo a de tornar juridicamente compreensíveis as noções de direito erigidas por grupos sociais historicamente sem acesso à justiça" (Leite, 2005, p. 21).

É no interior de uma miríade de situações e vozes que o antropólogo é chamado a agir. Cenário complexo, com forças e desequilíbrios que mostram a magnitude envolvida no trabalho. São diferentes espaços, tempos e discursos, imagens e projeções que atravessam a comunidade, e devem ser levados em conta pela sensibilidade do antropólogo, e assim passar a compor o procedimento. Há uma série de processos que estão intrincados, sobrepostos e relacionados ao reconhecimento das comunidades, estes que devem estar presentes e devem ser protegidos dos procedimentos homogeneizantes do Estado, que demandam critérios objetivos de classificação.

O papel do antropólogo é, portanto, cercado de dilemas, que passam pela condição que lhe é atribuída de assessor na tomada de decisões aos detentores do poder de fato da decisão, em seu "atuar como vértice no diálogo estabelecido entre os sujeitos do direito e os operadores do direito" (Stucchi, 2005, p. 313). 


\section{Considerações Finais}

A reflexão ora apresentada voltou-se, a partir da reflexão sobre o caso dos remanescentes de quilombos, aos limites e desafios do trabalho do antropólogo, bem como seu papel enquanto perito, frente aos processos de identificação étnica e territorial, que são, sobretudo, carregados de caráter político na interface do campo antropológico com o jurídico. Trata-se de direitos culturais, étnicos, sociais e fundiários, trata-se da emergência de novos sujeitos, em campo conflituoso caracterizado por múltiplas vozes, do micro ao macro, onde figura o Estado e seu dever de emitir a essas comunidades os respectivos títulos definitivos das terras que ocupam. A temática dos laudos de reconhecimento diz respeito, portanto, à identificação étnica e territorial, e colocam em cena a responsabilidade do profissional, uma vez que de seu trabalho pode depender o futuro daquele grupo.

Nesse sentido, os laudos periciais emergem como instrumentos de conhecimento de formas alternativas de vida para orientação da aplicação de direitos constitucionalmente assegurados, como 'história' para populações marcadas por conflitos, e de acordo com princípios éticos do trabalho do antropólogo, aqui carregado de singularidades em campo que supõe uma tomada de posição política de seu autor, este que teoriza a partir da realidade política local - presente - remetendo ao passado - pressuposto pelo preceito - para lançar luzes sobre direcionamentos, posicionamentos e questões futuras.

O antropólogo, que emerge enquanto mediador entre a comunidade e o Estado, deve respeitar não só a ética de sua profissão, mas também outras que vêm pela demanda. E, nesse sentido, o profissional obriga-se para com os interesses da comunidade, embora ciente de que a decisão vá residir em outra instância. O laudo dará então subsídios, pautado nas verdades e visões de seus informantes, dos que são os interessados, dos emergentes sujeitos de direito. É a partir desse compromisso com as visões de mundo da comunidade que o profissional produzirá o conhecimento demandado, este que se associa ao bem estar do grupo, devendo servir beneficamente aos mesmos.

Vale ser lembrada a situação de produção do trabalho, marcada por conflitos, étnicos, políticos e territoriais, onde o antropólogo está dedicado aos grupos desfavorecidos no que diz respeito a poder e condições materiais, e assim pode figurar como aliado e intercessor dos mesmos. O laudo pericial antropológico pode ser, então, tomado enquanto tentativa de dar voz a estes em instâncias jurídicas e políticas. E seus usos vão além, como instrumentos políticos; figuram tanto quanto a história escrita como a base da luta. O laudo é, 
nesse sentido, instrumento do conhecimento, usado no processo da visibilidade desses grupos, da busca pelo reconhecimento de direitos territoriais - e outros que deles decorrem - e valorização das suas identidades.

\section{Referências}

BRASIL. Constituição da República Federativa do Brasil. Brasília: 1988.

Associação Brasileira de Antropologia e Núcleo de Estudos sobre Identidade e Relações Interétnicas, ABA-Nuer/UFSC, 2000. Carta de Ponta das Canas. [Online]. Disponível em: <www.abant.org.br/conteudo/001DOCUMENTOS/DocumentosABA/cartacanas. pdf>. Acesso em: 22 dez. 2010.

Associação Brasileira de Antropologia, Gestão 1986-1988. Código de Ética do Antropólogo. [Online]. Disponível em: <www.abant.org.br/index.php?page=3.1>. Acesso em: 22 dez. 2010.

ALMEIDA, Alfredo W. B de. Quilombos: sematologia face a novas identidades. In: Frechal Terra de Preto: quilombo reconhecido como reserva extrativista. São Luís: SMDDH/CCN-PVN, 1997.

ALMEIDA, Alfredo Wagner B.; PEREIRA, Deborah Duprat de B. As populações remanescentes de quilombos - Direitos do passado ou garantia para o futuro? Seminário Internacional "As minorias e o Direito". In: Cadernos Sério, Cadernos do CEJ, v. 24, 2003.

ANJOS, José Carlos Gomes dos. Remanescentes de quilombos: reflexões epistemológicas. In: LEITE, I. B. (Org.). Laudos periciais antropológicos em debate. Florianópolis: Nuer/ABA, 2005.

ARRUTI, José Maurício P. A. A emergência dos 'remanescentes': notas para o dialogo entre indígenas e quilombolas. In: Mana, v. 3, n. 2, 1997.

. O quilombo conceitual: para uma sociologia do artigo 68 do ADCT. In: Texto para discussão: Projeto Egbé - Territórios negros (Koinonia), 2003.

Etnografia e história no Mocambo: notas sobre uma 'situação de perícia'. In: LEITE, I. B. (Org.). Laudos Periciais Antropológicos em Debate. Florianópolis: Nuer/ABA, 2005.

.Mocambo: antropologia e história do processo de formação quilombola. Bauru,

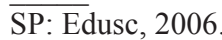

BARCELLOS, Daisy. Relatórios técnicos de identificação étnica e territórios tradicionais - o caso de Morro Alto. In: LEITE, I. B. (Org.) Laudos periciais antropológicos em debate. Florianópolis: Nuer/ABA, 2005.

BECKER, Simone. Breves Reflexões sobre intervenção e ética nos laudos antropológicos. In: LEITE, I. B. (Org.). Laudos periciais antropológicos em debate. Florianópolis: Nuer/ABA, 2005.

CARREIRA, Eliana de Amorim. O lugar da Antropologia no campo multidisciplinar do laudo. In: LEITE, I. B. (Org.). Laudos periciais antropológicos em debate. Florianópolis: Nuer/ABA, 2005.

DALLARI, Dalmo de Abreu. Argumento antropológico e linguagem jurídica. In: SILVA, O. S.; LUZ, L.; HELM, C. M. V. (Orgs.). A perícia antropológica em processos judiciais. Florianópolis: UFSC, 1994. 
GEERTZ, Clifford. O saber local: fatos e leis em uma perspectiva comparativa. In: GEERTZ, C. O saber local: novos ensaios em antropologia interpretativa. Petrópolis: Vozes, 1998.

LOPES DA SILVA, Aracy. Há antropologia nos laudos antropológicos? In: SILVA, O. S.; LUZ, L.; HELM, C. M. V. (Orgs.). A perícia antropológica em processos judiciais. Florianópolis: UFSC, 1994.

LEITE, Ilka Boaventura. Os quilombos no Brasil: questões conceituais e normativas. Etnográfica (Lisboa), Portugal, v. 4, n. 2, 2001.

. O legado do testamento: a comunidade da Casca em perícia. Florianópolis: Nuer/UFSC, 2002.

- Questões éticas da pesquisa antropológica na interlocução com o campo jurídico. In: VÍCTORA,Ceres et al. (Orgs.). Antropologia e ética: o debate atual no Brasil. Niterói: ABA e Eduff, 2004.

Os laudos periciais - um novo cenário na prática antropológica. In: LEITE, I. B. (Org.). Laudos periciais antropológicos em debate. Florianópolis: Nuer/ABA, 2006.

Os Quilombos e a Constituição Brasileira. In: OLIVEN, R. G.; RIDENTI, M.; BRANDÃO, G. M. (Orgs.). A Constituição de 1988 na vida brasileira. São Paulo: Hucitec/Anpocs, 2008.

O'DWYER, Elaine Cantarino. Quilombos: identidade étnica e territorialidade. Rio de Janeiro: FGV, 2006.

. Laudos antropológicos: pesquisa aplicada ou exercício profissional da disciplina? In: LEITE, I. B. (Org.). Laudos periciais antropológicos em debate. Florianópolis: Nuer/ABA, 2005.

OLIVEIRA FILHO, João Pacheco. Os instrumentos de bordo: expectativas e possibilidades do trabalho do antropólogo em laudos periciais. In: SILVA, O.; LUZ. L.; HELM, M. (Orgs.). A Perícia Antropológica em Processos Judiciais. Florianópolis: UFSC, 1995.

RIBEIRO, Gustavo Lins. Ofício da ABA ao Ministro Chefe da Casa Civil, 2003. In: LEITE, I. B. (Org.). Laudos periciais antropológicos em debate. Florianópolis: Nuer/ABA, 2005.

STUCCHI, Deborah. Percursos em dupla jornada: o papel da perícia antropológica e dos antropólogos nas políticas de reconhecimento de direitos. Tese (doutorado) Universidade Estadual de Campinas, Instituto de Filosofia e Ciências Humanas, 2005.

STUCCHI, Deborah; FERREIRA, Rebeca Campos. Singularidades culturais em processos de reconhecimento étnico: os filhos de Nossa Senhora do Carmo. Paper apresentado na $27^{\mathrm{a}}$ Reunião Brasileira de Antropologia, Associação Brasileira de Antropologia, ABA, Belém, Pará, 2010.

Os Pretos do Carmo diante do possível, porém improvável: uma análise sobre o processo de reconhecimento de direitos territoriais (no prelo). In: Revista de Antropologia, São Paulo: DA/FFLCH/USP, 2011. 